\title{
Cutting Performance Analysis of Surface Textured Tools in Dry Turning: Optimisation of process parameters
}

\author{
Rima Singha Roy ${ }^{1}$, Sushmita Dash $^{2}$, Trupti Ranjan Mahapatra ${ }^{3 *}$, Debadutta Mishra ${ }^{3}$ and Sanjib Jaypuria ${ }^{4}$ \\ ${ }^{1}$ Department of Mechanical Engineering, National Institute of Technology, Rourkela, Odisha, India \\ ${ }^{2}$ GITA Autonomous College, Bhubaneswar, Odisha, India \\ ${ }^{3}$ Department of Production Engineering, Veer Surendra Sai University of Technology, Burla, Odisha, India \\ ${ }^{4}$ Mechanical Engineering Department, Indian Institute of Technology Kharagpur, Kharagpur - 721302, India
}

\begin{abstract}
Owing to minimum quantity or no use of toxic coolants, the dry machining technique has been evidenced to be a versatile sustainable method. However, during dry machining of ductile alloys, the severe tool wear and metal adhesion on the rake face of the cutting tool has been a matter of great concern. In the present work, an attempt has been made to assess the improvement in the tribological conditions in dry cutting by providing surface texturing on the rake face of High-Speed Steel (HSS) cutting tool. Dimples were produced on the rake surface of the HSS tool using pulsed Nd: YAG Laser and dry turning of pure aluminium is performed using the textured tool based on Taguchi's L 9 orthogonal array (OA) experimental design. The dry cutting of pure aluminium was also performed using the conventional/un-textured tool and the obtained results are used for comparison purpose. Improved turning performance in terms of material removal rate and surface roughness is found from the conformation tests using optimum process parameter determined by the Taguchi analysis. The ANOVA results suggests the effectiveness of using the textured tools during dry machining is significantly affected by feed and speed.
\end{abstract}

Keywords: Dry Machining, Surface texturing, Taguchi's methodology, Cutting Force, Surface Roughness, ANOVA.

\section{Introduction}

Recently, there is quest for eco-friendly methods in metal cutting industries for attaining the environmental regulations and numerous investigations pertaining to the environment sustainable machining practises are being carried out. Dry machining has been proved to be an effective method in addressing this issue. It is well known that, in metal cutting operation significant amount of energy is lost as heat due to friction. In conventional machining processes the cutting forces those primarily involve the frictional force remains the most significant factor and needs to be controlled meticulously while machining. This is because, as nearly as $50 \%$ of the total energy supplied is lost due to friction in different metal cutting operations and subsequently get away in the form of heat and sound. Therefore, substantial efforts have been put by various researchers in the past to control the frictional force during machining. In this regard frequent attempts are made by utilizing diverse lubricants during conventional machining of metals and alloys. However, it is also true that with the growing demand for ecological machining and many harmful effects of the use of cutting fluids, the use of lubricants is being avoided. Thus, the dry machining which is also known as green machining has become an alternative, that utilises no or minimum quantity of cutting fluids. Moreover, the use of surface textured tools in dry machining has been an evolving topic in recent times due to its obligation for both green manufacturing as well as reduction of cutting forces along with tool life improvement.

Numerous researches on different machining operations under dry conditions have already been performed previously. It has been noticed that specific problems like reduced tool life and excessive material adhesion on the tool surface are always associated with the dry machining processes. In order to overcome these difficulties, some of the improved methods combined with dry machining are being proposed and implemented by many researchers for getting effective results. Such methods include the use of Minimum Quantity Lubricants (MQL) or Solid Lubricants $\left(\mathrm{MoS}_{2}, \mathrm{WS}_{2}, \mathrm{CaF}_{2}\right)$ that are less harmful than liquid coolants, coated tools such as chemical vapour deposition (CVD) or Physical vapour deposition (PVD) coated Tools (TiNi/AlCrNi coated tools), tools with chip breaker, surface textured tools (parallel/perpendicular/ dimple patterns on rake surface of tool), coated tools with surface texturing etc. As the texturing on the tools can be

*Corresponding author: trmahapatra pe@vssut.ac.in 
achieved with ease via non-traditional machining processes such as Electro Discharge Machining (EDM), wire EDM and Laser beam machining (LBM), surface texturing on the rake or flank face of the tool is one of the widely appreciated techniques which is recently being used by the scientific community. This method has also been found to be more effective in reducing the cutting force as well as achieving better performance in comparison to the un-textured tools. Therefore, wide amount of research work is being carried out in recent years in the domain of machining with the abovementioned technique alongside various other techniques on different metal cutting operations to know the effectiveness of the approach.

Dry machining is basically adopted for avoiding the toxic effects of the cutting fluids and hence research on near dry machining is being widely carried out every now and then to study the feasibility and reduce the amount of coolants usage. Carrilero et al.[1] studied the formations of builtup edge (BUE) and built-up layer (BUL) using TiN inserts in machining of A2024 and reported an initial formation of aluminium based metallic layer (BUL) owing to the compression forces between the tool and chip. They also noticed the formation BUE comprising highly similar elements to that of the original material with higher percentages of $\mathrm{Cu}$ and $\mathrm{Fe}$. Optimised tool geometry for the cutting conditions during drilling of aluminium alloys without the use of any lubricants has been developed by Nouari et al.[2] by using WC-Co cemented carbide drills with diamond coatings and informed that with larger cutting speed and a lower feed rates, a good surface quality holes can be achieved with high dimensional accuracy and improved tool life. Wiper inserts found to provide better surface roughness results than the conventional ones during dry turning operation on low $\mathrm{Cr}$ steel alloy using ceramic (TiC) tool with wiper and a conventional insert (Grzesik et al.[3]). It has also been revealed (Asad et al.[4]) that an optimised model could be prepared providing good results relating to the experimental values for cutting forces and chip formation during dry machining using A2024. Lee et al.[5] used a pulse shaper technique based on a modified split Hopkinson pressure bar (SHPB) for attaining the parametric values to study the deformation behaviour of $\mathrm{Al}-\mathrm{Cu}$ and $\mathrm{Al}-\mathrm{Mg}-\mathrm{Si}$ alloy at different temperatures which could be further used in different equations such as Johnson's Cook Material Model. The Response Surface Methodology (RSM) technique has been reported to be fitting best for providing approximate values of the desired responses (Andriya et al.[6]) while machining of Ti-6Al-4V with PVD coated tools and no use of coolants. Parra et al.[7] investigated the formation of BUL and BUE mechanisms and their influence during dry turning of aeronautical aluminium alloys and depicted the existence of a relationship between the surface finish of the machined material and the adhesion effects. The average surface roughness ( $\mathrm{Ra}$ ) values are found to be proportional to the feed and effective results are obtained at lower feed and higher nose radii during turning experiments on Al6061T6 using Polycrystalline diamond (PCD) tool (Kalyan et al.[8]). Torres et al.[9] noticed the interaction between feed and depth of cut to be the most effective parameter, with feed giving satisfactory influence on $\mathrm{Ra}$ values during turning of A2024 aluminium alloy. Further, the dry cool environment is found to provide better results for chip formation (Eapen et al.[10]). However, the PCD tool has been proved to give better results pertaining to tool wear, chips and surface roughness (Pattnaik et al.[11]). Further, the application of high-frequency vibration to rotary tool, tend to reduce the cutting force and surface roughness while turning of A7075 (Teimouri et al.[12]). Shi et al.[13] reported the benefit of dots (raised with the help of laser powder cladding method and acted as chip breaker) on the rake face of the High Speed Steel (HSS) tool for turning experiments using aluminium alloy. Rao et al.[14] conducted experiments to find the residual stress and micro hardness induced while the computer numerical control (CNC) turning of A7075. Results showed that the residual stress values were higher trend at lower cutting speeds and vice-versa whereas the stress increased with increasing depth of cut. Chen et al.[15] conducted milling experiments to study the surface deformations while machining at high speed on A7055 by PED assisted nano scale orientation mapping and TEM. Micro structural changes were noticed under thermo-mechanical effect. Kannan and Ghosh[16] proposed a coating (Gr-X) which is a solid composite lubricant, to restrict the creation of BUE and BUL while dry machining of AA2024 alloy. Graphite-PTFE soft composite coating ( $\mathrm{Gr}-\mathrm{x})$ proved to be better than $\mathrm{MoS}_{2}$ in favour of machining aluminium under humid environment. Owing to the ever-pressing demand from the market, the manufacturing industries need constant improvements to achieve better productivity. In order to do so, more sustainable machining techniques are being developed which includes the fabrication of patterns over the flank face or the rake face of cutting tool which has shown to provide effective results through decrease in cutting temperature, forces, tool wear as well as coefficient of friction. Numerous works pertaining to different surface textures on the tool surface are available in open literature. Some of the relevant studies are discussed here to make the study selfstanding: Sugihara and Enomoto et al.[17] performed face-milling experiments using aluminium alloy to show the significance of nano/micro-textured surface and revealed that the tool with banded grooves was most effective to improve the anti-adhesive property. They [18] further fabricated tools with textures through femtosecond laser technology and conducted Face-milling experiments on aluminium alloys revealing that textured tools and DLC coated tools enhance the anti-adhesive and lubricity properties. Obikawa et al.[19] conducted orthogonal machining experiments on A6061 using micro textured tools with and without coating for obtaining responses such as coefficient of friction and cutting forces and found that the square and parallel dot type textures with smaller and deeper dimensions have positive effect on the cutting conditions. Also, the textures with coating served to improve the lubrication conditions effectively. Ze et al.[20] conducted dry cutting experiments on Ti-6Al-4V with conventional tool and textured tools embedded with solid lubricant. The cutting performance was evaluated by obtaining the chip thickness ratio, cutting temperature, 
tool wear and cutting forces. They revealed that the cutting temperature with the force values of textured tools is lower in comparison to the conventional tool. The tool with elliptical pattern on rake surface showed reduction in the chip thickness ratio, tool-chip contact and friction coefficient. Also, the life of the textured tool showed improvement to that of conventional tool. Sugihara and Enomoto et al.[21] developed milling tools with various textured patterns to improve the tool life by reducing the crater wear and flank wear. They studied the effect of the dimensions of the texture patterns on tool wear resistance. The results showed that tool with textured surface both at the rake and the flank surface significantly improved the tool life and the textures on the flank surface helped in reducing the flank wear. Kummel et al.[22] developed textures like dimples and channels on the rake face of the cemented carbide tools by laser surface texturing and performed dry turning on SAE1045 to investigate the degree of reducing the formation of BUE on different texture patterns with respect to un-textured tools. In their study, the dimple pattern showed better results on stabilising the generation of BUE than the channel texture pattern. Senthilkumar et al. [23] conducted dry machining on Ti-6Al-4V using textured tools and also carried out numerical simulation using Deform 3D software. Cutting forces, cutting temperature and chip morphology were studied both for textured as well as un-textured tools and experimental results were validated with the simulated results. Their results show that the textured pattern perpendicular to the direction of chip flow showed highest decrease in cutting temperature and forces as well as enhanced tool life. Kurniawan et al.[23] fabricated microdimple pattern using elliptical vibration texturing (EVT) based on the EVC method using the PCD insert. They prepared an analytical model of the texturing process to analyse orthogonal cutting force during turning operation. Arulkirubakaran and Senthilkumar [24] developed textured patterns on the rake face of the tools with and without coating and conducted turning operation on $\mathrm{Ti}$ $6 \mathrm{Al}-4 \mathrm{~V}$ to evaluate the effectiveness of both coated as well as uncoated tools with textures. The effectiveness was measured using parameters such as tool wear, cutting forces, chip formation and surface roughness. Results showed Ti-Al-N coated tool with perpendicular texture pattern performed better than all other tools. Sasi et al.[25] produced micro dimple texture patterns on the rake surface of the HSS tool with the help of pulsed Nd: YAG laser and conducted orthogonal dry turning experiments using Al7075-T6 as work piece material. The comparison of the performance of textured tool with the conventional tools showed that the use of textured tools helps in reducing the cutting forces and could be effectively used while machining soft materials such as aluminium. Zhang et al.[26] proposed ultrasonic elliptical vibration-assisted cutting technique to develop hybrid micro-textures with different geometry and revealed that the elliptical vibration assisted hybrid dimples could be developed satisfactorily on cylindrical work pieces. Dhage et al.[27] studied the effect of surface texture parameters of cutting tools on friction conditions at tool-chip interface during dry machining of AISI 1045 steel. They found that skewness, kurtosis and other surface texture limitations on the rake surface significantly affect the machining forces by changing friction condition at the tool-chip interface. Law et al.[28] analysed finish turning of a hardened bearing steel with the help of PcBN tools having 12 types different textures. Textures were made using laser and focused ion beam. They found that cutting performance considered by tool life, cutting forces and workpiece surface roughness is rather independent of the texture shape, size, orientation, spacing and location. Qinghua et al.[29] studied the effects of micro textures on tool wear and machined surface roughness by analysing cutting force, Mises stress and maximum shear stress of tool surface on hardened GCr15 with PCBN tools having micro hole textures having different forms. They found that micro hole structure can greatly improve tool wear and can also improve machined surface quality. Rajbongshi et al.[30] studied the performance parameters in machining of AISI D2 steel using dot-textured, groovetextured and non-textured cutting tool at the flank face. They found that surface roughness is less for both type of textured tool than non-textured tool. From the brief review of literature, it has been found that, the use of textured tools in various machining operations have been a subject of acute interest in recent times as it is found to be more effective in improving the tribological properties of dry machining processes in particular. However, owing to no use of fluids there is always a chance of rise in cutting temperature which in turn leads to reduction in tool life as well as the formation of built-up edge (BUE) and built-up layer (BUL). In this regard, limited research works have been reported for HSS as cutting tool material. We note that various grades of steels are yet to be explored for their cutting performance analysis using textured HSS cutting tool during dry machining operation.

Therefore, the present research aims to explore the effect of texturing during the dry turning operation of pure aluminium (A1100) which finds a wide spread industrial application. The machining is carried out using commercially available HSS T42S400 tool having dimple type surface textures on the rake surface. The desired dimples are perforated via micromachining with the aid of the Pulsed Nd: YAG laser micro drilling machine. The cutting forces and surface roughness are obtained for both the textured and un-textured tool and the optimization of cutting parameters in dry turning using textured tool is done implementing Taguchi optimization technique

\section{Experimental Procedure and Methodology}

The possibility of dry machining of pure Aluminium using textured HSS tool is studied. Laser Micromachining has been used for creating textures on the surface of the HSS. The Pulsed Nd: YAG laser is being used which creates dimple textures on the HSS surface with ease. Further to achieve a comparative analysis the tool performance with texture and without texture has also been investigated. The cutting force and surface roughness are taken as performance measurement indicator. 


\subsection{Tool and Workpiece Materials}

The workpiece material used is pure Aluminium (A1100) which has its wide application in areas such as heat exchanger fins, cooking utensils, different sheet metal works to name a few. The workpiece used is in rolled form i.e., a cylindrical round bar of diameter $150 \mathrm{~mm}$ and length of $500 \mathrm{~mm}$. The composition and properties of A1100 is specified in Table 1 and 2, respectively.

Table 1. Chemical composition of workpiece (A1100)

\begin{tabular}{|c|c|}
\hline Element & \% Content \\
\hline Aluminium & 99 \\
\hline Copper & 0.12 \\
\hline
\end{tabular}

Table 2. Properties of Pure Al

\begin{tabular}{|c|c|}
\hline Density & $2.71 \mathrm{~g} / \mathrm{cm}^{3}$ \\
\hline Elastic Modulus & $70-80 \mathrm{GPa}$ \\
\hline Poisson's Ratio & 0.33 \\
\hline Thermal Conductivity & $218 \mathrm{~W} / \mathrm{mK}$ \\
\hline Thermal Expansion & $23.6 \times 10^{-6} /{ }^{\circ} \mathrm{C}$ \\
\hline Machinability & Excellent \\
\hline
\end{tabular}

The tool material selected for the current study is HSS T42. The chemical composition and the properties of HSS T42 are given in Table 3 and 4, respectively. The tool bits were supplied by Miranda Tools, Gujarat, India with dimensions as $19.05 \mathrm{~mm}$ square sides and $152.04 \mathrm{~mm}$ length. The tool bits were then provided with different angles as best required for machining aluminium through grinding process.

Table 3. Chemical composition of the tool (HSS) material

\begin{tabular}{|c|c|c|c|}
\hline Element & \% Content & Element & \% Content \\
\hline $\mathrm{C}$ & $1.25-1.40$ & $\mathrm{Cr}$ & $3.75-4.50$ \\
\hline $\mathrm{Si}$ & $0.00-0.40$ & $\mathrm{Mo}$ & $2.75-3.50$ \\
\hline $\mathrm{Mn}$ & 0.35 & $\mathrm{~V}$ & $2.75-3.25$ \\
\hline $\mathrm{P}$ & 0.35 & $\mathrm{~W}$ & $8.50-9.50$ \\
\hline $\mathrm{S}$ & 0.35 & $\mathrm{Co}$ & $9.00-10.00$ \\
\hline $\mathrm{Ni}$ & $0.00-0.40$ & & \\
\hline
\end{tabular}

Table 4. Properties of HSS used as tool material

\begin{tabular}{|c|c|}
\hline Young's Modulus & $235 \mathrm{GPa}$ \\
\hline Poisson's Ratio & 0.28 \\
\hline Tensile strength & $750 \mathrm{MPa}$ \\
\hline Thermal Conductivity & $44-65 \mathrm{~W} / \mathrm{m} \mathrm{K}$ \\
\hline Density & $7700 \mathrm{Kg} / \mathrm{m}^{3}$ \\
\hline Specific Heat & $430 \mathrm{~J} / \mathrm{Kg} . \mathrm{K}$ \\
\hline
\end{tabular}

\subsection{Development of Textured Tool}

After the generation of angles, the tools are cleaned and prepared (Fig. 1 (a)) for the dimples to be fabricated on the rake face of the tool near the main cutting edge. The dimples of diameter $0.1 \mathrm{~mm}$ are perforated at distance of about $0.1 \mathrm{~mm}$ and the approximately the area covered was about $5 \mathrm{~mm}^{2}$ (Fig. 1 (b)). The other details are explained in the subsequent section. For producing dimples on the rake surface of HSS T42 tools CNC pulsed Nd: YAG laser system by M/S Sahajanand Laser Technology, India available in the Advanced Machining Laboratory, Department of Production Engineering, VSSUT, Burla was used (Fig. 1 (c)). Prior to the fabrication of dimples, the tools were thoroughly cleaned with the help of acetone to remove grease, stain and dirt. Subsequently, it was finely polished with abrasive sheets of P360 and P1500 to obtain a highly polished smooth surface.

For the creation of dimples on the rake surface of the HSS tool using Nd: YAG laser, the frequency, scanning speed and current were taken as the process parameters. Owing to lesser number of works available in open literature related to dimples using the above-mentioned parameters, hit and trial method was used for achieving the optimum combination of parameters to perform the micromachining operation. From the literature review it has been noticed that the major parameters affecting the laser micromachining processes are wavelength, frequency, pulse energy, pulse width and pulse duration. For the creation of dimples on the rake surface of the HSS tool using Nd: YAG laser, the frequency, scanning speed and current were taken as the process parameters. Owing to lesser number of works available in open literature related to dimples using the above-mentioned parameters, hit and trial method was used for achieving the optimum combination of parameters to perform the micromachining operation. Thus, dimples of approximate size of about $0.2 \mathrm{~mm}$ diameter and $0.1 \mathrm{~mm}$ depth were fabricated at frequency $3 \mathrm{KHz}$, scanning speed $10 \mathrm{~mm} / \mathrm{sec}$ and current $28 \mathrm{amps}$. Throughout the perforation process the wavelength is kept constant as $1064 \mathrm{~nm}$. Due to low absorptivity of HSS at this wavelength the dimples fabricated were found to be shallow and lumps of material was found to be deposited on the edges of the dimples with heat affected zone created around it. This can be reduced with the use of an assisted gas such as the Argon.

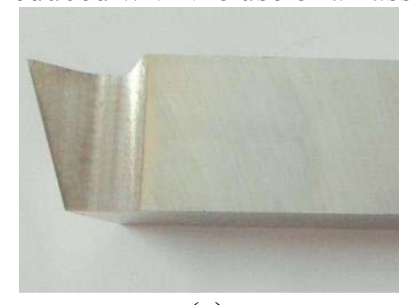

(a)

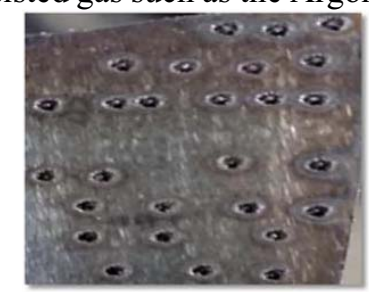

(b)

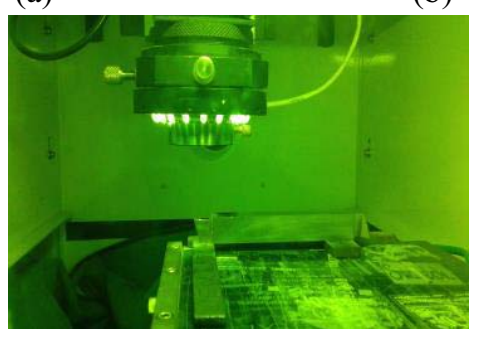

(c)

Fig. 1. (a) HSS T-42 tool (b) Fabrication of Dimples on the rake surface near the nose radius (c) Producing dimples on the rake surface through Nd: YAG laser

In order to achieve more efficacy of texturing while machining, the dimples were perforated near the main cutting edge which is near the nose or tip of the tool. Before performing the experiments, the trial experiments were conducted on different rough specimens and different patterns such as grooves and dimples were produced to assess the type of pattern that could be best produced using the available Nd: YAG laser. Based on the 
results, it has been decided to produce dimples as these can be generated with higher depth than the grooves. Also, for the cutting inserts the texturing was not visible properly even after changing the parameters. This may be due to the low power (100Watt) associated with the available laser.

\subsection{Dry Turning and Design of Experiments}

The experiment was conducted on a Capstan and Turret Lathe which are basically used for mass production (available at the Department of Mechanical Engineering,

\subsection{Optimization of Dry Turning Operation}

As mentioned earlier, the design of experiment for dry turning operation was made using Taguchi's design of experiment. The and the corresponding $\mathrm{L}_{9}$ orthogonal array and responses such as cutting force and surface roughness values obtained are shown in Table 6 . The results were analysed as well as the process parameters affecting the responses and their significance were studied by the analysis of variance (ANOVA) for both the textured and conventional tools. Then, optimized parametric levels were predicted. The whole optimization is done by using Minitab 18 software.

Table 6. Design of Experiments (Taguchi's L9 orthogonal array) and experimental results

\begin{tabular}{|c|c|c|c|c|c|c|c|c|c|c|}
\hline Sl. & Cutting Speed & Feed & \multicolumn{4}{|c|}{ Untextured } & \multicolumn{4}{c|}{ Textured } \\
\cline { 5 - 11 } No. & $(\mathrm{m} / \mathrm{min})$ & $(\mathrm{mm} / \mathrm{rev})$ & $\mathrm{F}_{\mathrm{x}}(\mathrm{N})$ & $\mathrm{F}_{\mathrm{y}}(\mathrm{N})$ & $\mathrm{F}_{\mathrm{z}}(\mathrm{N})$ & $\mathrm{R}_{\mathrm{a}}(\mathrm{mm})$ & $\mathrm{F}_{\mathrm{x}}(\mathrm{N})$ & $\mathrm{F}_{\mathrm{y}}(\mathrm{N})$ & $\mathrm{F}_{\mathrm{z}}(\mathrm{N})$ & $\mathrm{R}_{\mathrm{a}}(\mathrm{mm})$ \\
\hline 1 & 100 & 0.045 & 38 & 15 & 60 & 0.884 & 30 & 10 & 45 & 0.766 \\
\hline 2 & 100 & 0.125 & 50 & 20 & 95 & 1.18 & 42 & 15 & 82 & 0.925 \\
\hline 3 & 100 & 0.25 & 75 & 25 & 165 & 1.326 & 65 & 18 & 150 & 1.003 \\
\hline 4 & 125 & 0.045 & 35 & 10 & 57 & 1.058 & 27 & 10 & 43 & 0.905 \\
\hline 5 & 125 & 0.125 & 48 & 18 & 100 & 1.247 & 40 & 13 & 85 & 1.038 \\
\hline 6 & 125 & 0.25 & 74 & 23 & 160 & 1.288 & 68 & 20 & 138 & 1.115 \\
\hline 7 & 150 & 0.045 & 32 & 12 & 55 & 1.135 & 25 & 11 & 40 & 0.951 \\
\hline 8 & 150 & 0.125 & 52 & 15 & 98 & 1.355 & 45 & 14 & 80 & 1.125 \\
\hline 9 & 150 & 0.25 & 70 & 20 & 153 & 1.432 & 60 & 17 & 125 & 1.118 \\
\hline
\end{tabular}

VSSUT, Burla). A 3-axis piezoelectric dynamometer was attached for the measurement of forces along $\mathrm{x}, \mathrm{y}$ and $\mathrm{z}$ directions while turning operation is performed.

For analysing the performance of textured tools and compare it with the conventional tool, dry turning experiments were carried using both textured as well as the conventional tools. In order to avoid time consuming and expensive test procedures during experimentation, L9 orthogonal array was selected based on Taguchi's methodology and accordingly the cutting performance was analysed based on responses such as cutting forces, surface roughness and chip formation. By varying the process parameters such as the feed, cutting speed into three different levels and keeping the depth of cut constant at $0.5 \mathrm{~mm}$, the dry turning experiments were performed on both the textured as well as the conventional tools. The parameters with the presently selected levels is shown in Table 5.

Table 5. Input Parameters with Levels

\begin{tabular}{|c|c|c|c|}
\hline Parameters & Level 1 & Level 2 & Level 3 \\
\hline Cutting Speed (m/min) & 100 & 125 & 150 \\
\hline Feed (mm/rev) & 0.045 & 0.125 & 0.250 \\
\hline
\end{tabular}

\section{Results and Discussion}

Firstly, using Nd: YAG laser, dimples were fabricated on the rake surface of the HSS tool and the performance of both conventional as well as textured tools were analysed. After finding out the optimised parametric levels for dry turning operation as discussed in the subsequent sections, the quantitative analysis is also done by the authors in their later work. The results obtained during dry machining experimentation is analysed and discussed.

\subsection{Effect of cutting speed and feed on cutting forces}

From the response table of means (Table 7) it is clearly seen that feed turns out to be an effective parameter than cutting speed as feed is ranked 1 and the delta which is the difference between the highest mean value to the lowest mean value is also very high for feed in the case of conventional as well as dimpled tools which proves feed to be an effective parameter. As we need the force values as least as possible, hence the values with the least mean values are the most effective parameters which is feed that is most effective at level $1(0.045 \mathrm{~mm} / \mathrm{rev})$ and speed which turns out to be insignificant is lowest at level 3 (100 $\mathrm{m} / \mathrm{min}$ ).

Table 7. Response Table for means

\begin{tabular}{|c|c|c|c|c|}
\hline & \multicolumn{2}{|c|}{ Conventional } & \multicolumn{2}{c|}{ Textured } \\
\hline Level & $\begin{array}{c}\text { Cutting } \\
\text { speed } \\
(\mathrm{m} / \mathrm{min})\end{array}$ & $\begin{array}{c}\text { Feed } \\
(\mathrm{mm} / \mathrm{rev})\end{array}$ & $\begin{array}{c}\text { Cutting } \\
\text { speed } \\
(\mathrm{m} / \mathrm{min})\end{array}$ & $\begin{array}{c}\text { Feed } \\
(\mathrm{mm} / \mathrm{rev})\end{array}$ \\
\hline 1 & 60.33 & 34.89 & 50.78 & 26.78 \\
\hline 2 & 58.33 & 55.11 & 49.33 & 46.22 \\
\hline 3 & 56.33 & 85.00 & 46.33 & 73.44 \\
\hline Delta & 4.00 & 50.11 & 4.44 & 46.67 \\
\hline Rank & 2 & 1 & 2 & 1 \\
\hline
\end{tabular}

From the Main Effect Plots for Means in Fig 2 (a) and (b), respectively it is noticed that feed is an effective parameter than cutting speed as it covers more slope than cutting speed. So, feed can be concluded as an effective parameter for dry turning operation for both textured and un-textured tools at level 1 which is $0.045 \mathrm{~mm} / \mathrm{rev}$.

The $\mathrm{S} / \mathrm{N}$ ratio values and the response table for $\mathrm{S} / \mathrm{N}$ ratio is presented in Table 8 (a) and (b), respectively. It can be inferred that, the level with highest $\mathrm{S} / \mathrm{N}$ ratio is speed of $150 \mathrm{~m} / \mathrm{min}$ and feed of $0.045 \mathrm{~mm} / \mathrm{rev}$ and this combination 
can be taken as the most effective parameter level. Similar behaviour can also be observed with main effect plots of $\mathrm{S} / \mathrm{N}$ ratios as shown in Fig 3 (a) and (b) for conventional and textured tools, respectively.

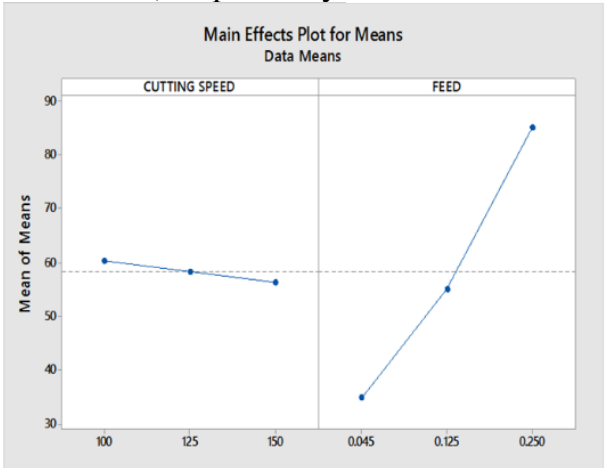

(a)

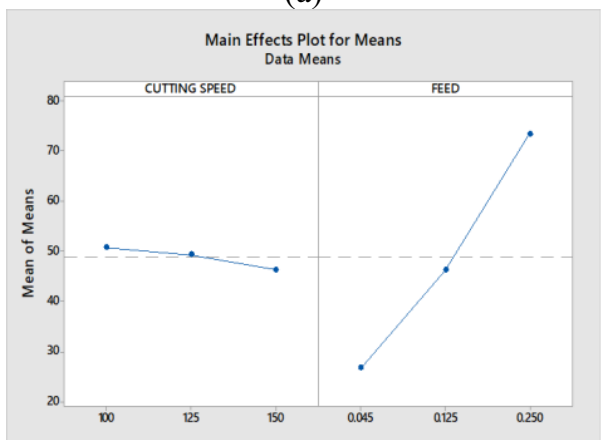

(b)

Fig. 2. Main Effect Plots for Means (a) Conventional tool, (b) Textured tool

Table 8. (a) $\mathrm{S} / \mathrm{N}$ Ratio for cutting forces $\left(\mathrm{F}_{\mathrm{x}}, \mathrm{F}_{\mathrm{y}}, \mathrm{F}_{\mathrm{z}}\right)$

\begin{tabular}{|c|c|c|c|}
\hline $\begin{array}{c}\text { Cutting Speed } \\
(\mathrm{m} / \mathrm{min})\end{array}$ & $\begin{array}{c}\text { Feed } \\
(\mathrm{mm} / \mathrm{rev})\end{array}$ & $\begin{array}{c}\text { S/N ratio } \\
(\text { Conventional })\end{array}$ & $\begin{array}{c}\text { S/N ratio } \\
(\text { Textured })\end{array}$ \\
\hline 100 & 0.045 & -32.4461 & -30.0360 \\
\hline 100 & 0.125 & -35.9934 & -34.6305 \\
\hline 100 & 0.250 & -40.4760 & -39.5503 \\
\hline 125 & 0.045 & -31.8317 & -29.5069 \\
\hline 125 & 0.125 & -36.2421 & -34.7683 \\
\hline 125 & 0.250 & -40.2263 & -39.0432 \\
\hline 150 & 0.045 & -31.4540 & -28.9321 \\
\hline 150 & 0.125 & -36.2093 & -34.5844 \\
\hline 150 & 0.250 & -39.8090 & -38.1323 \\
\hline
\end{tabular}

Table 8. (b) Response Table for $\mathrm{S} / \mathrm{N}$ Ratio

\begin{tabular}{|c|c|c|c|c|}
\hline & \multicolumn{2}{|c|}{ Conventional } & \multicolumn{2}{c|}{ Textured } \\
\hline Level & $\begin{array}{c}\text { Cutting } \\
\text { speed } \\
(\mathrm{m} / \mathrm{min})\end{array}$ & $\begin{array}{c}\text { Feed } \\
(\mathrm{mm} / \mathrm{rev})\end{array}$ & $\begin{array}{c}\text { Cutting } \\
\text { speed } \\
(\mathrm{m} / \mathrm{min})\end{array}$ & $\begin{array}{c}\text { Feed } \\
(\mathrm{mm} / \mathrm{rev})\end{array}$ \\
\hline 1 & -36.31 & -31.91 & -34.74 & -29.49 \\
\hline 2 & -36.10 & -36.15 & -34.44 & -34.66 \\
\hline 3 & -35.82 & -40.17 & -33.88 & -38.91 \\
\hline delta & 0.48 & 8.26 & 0.86 & 9.42 \\
\hline rank & 2 & 1 & 2 & 1 \\
\hline
\end{tabular}

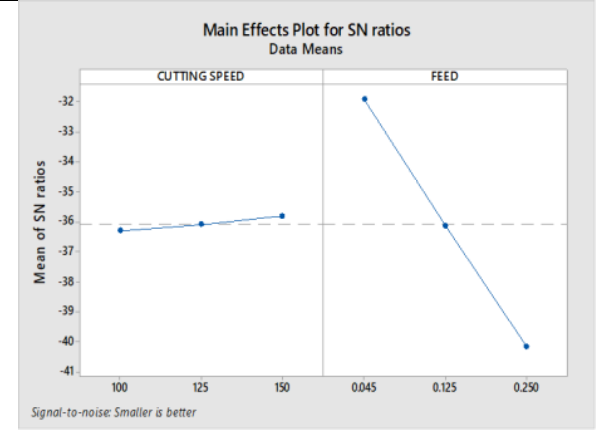

(a)

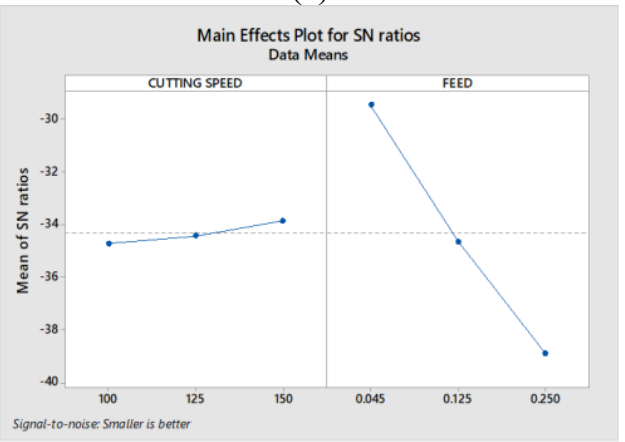

(b)

Fig. 3. Main effect plots for $\mathrm{S} / \mathrm{N}$ Ratios (a) Conventional tool, (b) Textured tool

\subsection{Effect of Cutting Speed and Feed on $\mathbf{R}_{\mathrm{a}}$}

For the case of surface roughness values the feed is ranked 1 (Table 9), hence feed turns out to be an effective parameter for dry turning operation for both the tools. It is also seen that the effect of cutting speed also exists but not as much effective as the feed.

Table 9. Response Table for Means

\begin{tabular}{|c|c|c|c|c|}
\hline \multirow{2}{*}{ Level } & Conventional & \multicolumn{3}{|c|}{ Textured } \\
\cline { 2 - 5 } & $\begin{array}{c}\text { Cutting speed } \\
(\mathrm{m} / \mathrm{min})\end{array}$ & $\begin{array}{c}\text { Feed } \\
(\mathrm{mm} / \mathrm{rev})\end{array}$ & $\begin{array}{c}\text { Cutting } \\
\text { speed } \\
(\mathrm{m} / \mathrm{min})\end{array}$ & $\begin{array}{c}\text { Feed } \\
(\mathrm{mm} / \mathrm{rev})\end{array}$ \\
\hline 1 & 1.130 & 1.026 & 0.8980 & 0.8740 \\
\hline 2 & 1.198 & 1.261 & 1.0193 & 1.0293 \\
\hline 3 & 1.307 & 1.349 & 1.0647 & 1.0787 \\
\hline Delta & 0.177 & 0.323 & 0.1667 & 0.2047 \\
\hline Rank & 2 & 1 & 2 & 1 \\
\hline
\end{tabular}

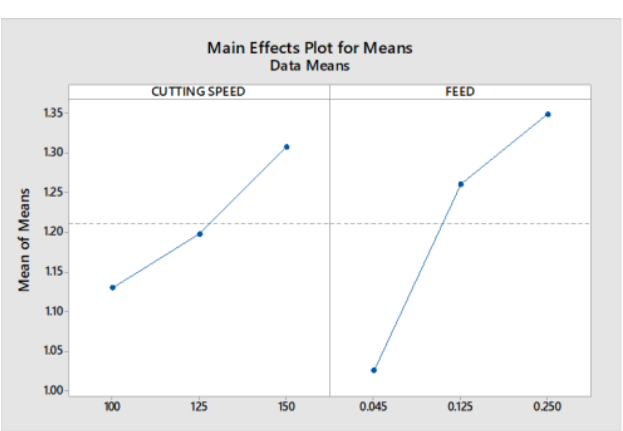

(a) 


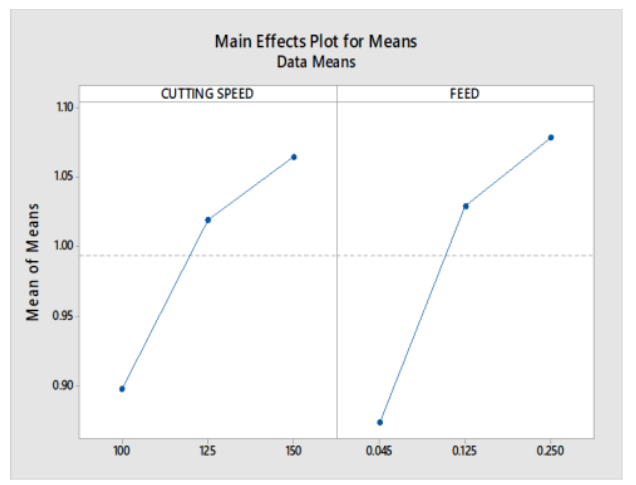

(b)

Fig. 4. Main effect plots for Means (a) Conventional tool, (b) Textured tool

From the graph showing the main effect plot (Fig 4 (a) and (b) for conventional and textured tools, respectively) for means describes that the more slope is covered by the feed. Hence, feed could be said as an effective parameter than speed whereas for dimpled tools the graph shows more effectiveness.

Table 10. (a) Response Table for $\mathrm{S} / \mathrm{N}$ Ratios

\begin{tabular}{|c|c|c|c|c|}
\hline \multirow[b]{2}{*}{ Level } & \multicolumn{2}{|c|}{ Conventional } & \multicolumn{2}{|c|}{ Textured } \\
\hline & $\begin{array}{l}\text { Cutting } \\
\text { speed } \\
(\mathrm{m} / \mathrm{min})\end{array}$ & $\begin{array}{c}\text { Feed } \\
(\mathrm{mm} / \mathrm{rev})\end{array}$ & $\begin{array}{l}\text { Cutting } \\
\text { speed } \\
(\mathrm{m} / \mathrm{min})\end{array}$ & $\begin{array}{c}\text { Feed } \\
(\mathrm{mm} / \mathrm{rev})\end{array}$ \\
\hline 1 & 0.9889 & 1.2063 & -0.9392 & -0.1729 \\
\hline 2 & -0.1341 & -0.2233 & -1.5351 & -1.9979 \\
\hline 3 & -0.5185 & -0.6468 & -2.2859 & -2.5893 \\
\hline Delta & 1.5074 & 1.8531 & 1.3467 & 2.4165 \\
\hline Rank & 2 & 1 & 2 & 1 \\
\hline
\end{tabular}

Table 10 (b) $\mathrm{S} / \mathrm{N}$ Ratios for $\mathrm{R}_{\mathrm{a}}$

\begin{tabular}{|c|c|c|c|}
\hline $\begin{array}{c}\text { Cutting Speed } \\
(\mathrm{m} / \mathrm{min})\end{array}$ & $\begin{array}{c}\text { Feed } \\
(\mathrm{mm} / \mathrm{rev})\end{array}$ & S/N Ratio & S/N Ratio \\
\hline 100 & 0.045 & 1.07095 & 2.315420 \\
\hline 100 & 0.125 & -1.43764 & 0.677165 \\
\hline 100 & 0.250 & -2.45087 & -0.026020 \\
\hline 125 & 0.045 & -0.48971 & 0.867028 \\
\hline 125 & 0.125 & -1.91733 & -0.323947 \\
\hline 125 & 0.250 & -2.19832 & -0.945497 \\
\hline 150 & 0.045 & -1.09992 & 0.436390 \\
\hline 150 & 0.125 & -2.63879 & -1.023050 \\
\hline 150 & 0.250 & -3.11886 & -0.968836 \\
\hline
\end{tabular}

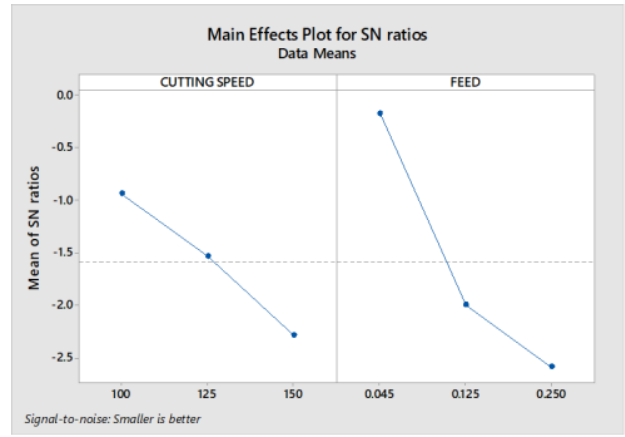

(a)

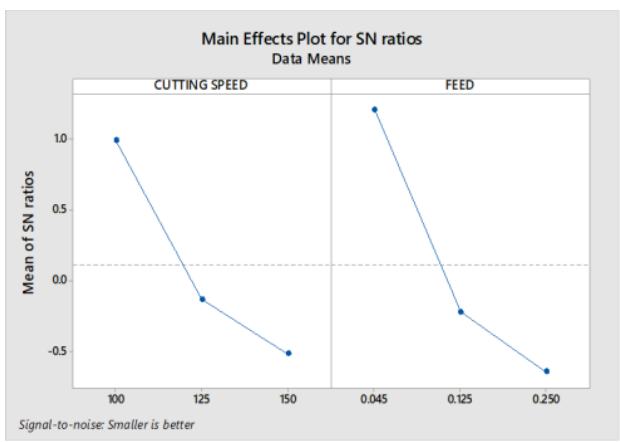

(b)

Fig. 5. Main effect plots for $\mathrm{S} / \mathrm{N}$ Ratios (a) Conventional tool, (b) Textured tool

From Table 10 (a) and (b) and Fig 5 it is observed from the $\mathrm{S} / \mathrm{N}$ ratio values that the highest $\mathrm{S} / \mathrm{N}$ ratio value occurs for speed $100 \mathrm{~m} / \mathrm{min}$ and feed $0.045 \mathrm{~mm} / \mathrm{rev}$. Hence, this level could be said as an optimum parametric level for the surface roughness while dry turning operation by using both the tools.

\subsection{Analysis of variance (ANOVA)}

The ANOVA analysis is performed using dimpled tools for dry turning operation as dimpled tools provided better results for means and $\mathrm{S} / \mathrm{N}$ Ratios for both cutting force and surface roughness.

ANOVA is basically carried out to find out the significant factor that has highest impact on the responses. In the present analysis, the variability in $\mathrm{S} / \mathrm{N}$ ratios is being analysed and then the final outcome is represented in a tabular form showing mean square values, standard deviations, contributions to variability by each parameter and an error value.

From the results provided in the following tables (Table 11 (a)-(f)) it can be seen that the value of $F$ is less than 4, thus indicating the cutting speed to be an insignificant factor. In contrary, the feed giving much higher value of $F$ proves to be significant. The same in the case for $P$ value which is greater than 0.05 showing cutting speed as insignificant and feed as significant for all the forces along $\mathrm{x}, \mathrm{y}, \mathrm{z}$ directions using textured tools as well as conventional tools. It is further noted that the dimpled tools showed better results than conventional ones.

From the results provided for the surface roughness values in the above tables (Table 12 (a)-(b)) it is observed that the values of $F$ is more than 4 for both the cutting speed and feed, hence both the parameters could be said to be significant but the value of $F$ is more in feed showing feed as more significant in comparison to cutting speed. The same can also be observed for the P values showing feed to be more significant for both the conventional as well as the dimpled tools. However, the dimpled tools showed better results than the conventional ones.

The normal probability plots are plotted considering the force values using both the dimpled and the conventional tools alongside the Anderson Darling test and presented in Fig 6 (a), (b) and (c) for $F_{x}, F_{y}$ and $F_{z}$, respectively. It is verified that the data of the model follows a distribution and fits the model. It is observed that the dimpled tools 
proved to provide better values than of $\mathrm{P}$ which is greater than 0.05 than the
Table 11. (d) Analysis of Variance Fy (Textured)

\begin{tabular}{|c|c|c|c|c|c|c|c|}
\hline Source & DF & Seq SS & Contribution & Adj SS & Adj MS & F-Value & P-Value \\
\hline Cutting Speed & 2 & 0.222 & $0.21 \%$ & 0.2222 & 0.1111 & 0.06 & 0.940 \\
\hline Feed & 2 & 96.222 & $92.92 \%$ & 96.2222 & 48.1111 & 27.06 & 0.005 \\
\hline Error & 4 & 7.111 & $6.87 \%$ & 7.1111 & 1.7778 & & \\
\hline Total & 8 & 103.556 & $100.00 \%$ & & & & \\
\hline \multicolumn{7}{|c|}{ Model Summary } \\
\cline { 2 - 5 } & \multicolumn{7}{|c|}{ R-sq R-sq(adj) R-sq(pred) } \\
\cline { 2 - 5 } & 1.33333 & $93.13 \% \quad 86.27 \%$ & $65.24 \%$ & \\
\hline
\end{tabular}

Table 11. (c) Analysis of Variance Fy (Conventional)

\begin{tabular}{|c|c|c|c|c|c|c|c|}
\hline Source & DF & Seq SS & Contribution & Adj SS & Adj MS & F-Value & P-Value \\
\hline Cutting speed & 2 & 29.556 & $14.91 \%$ & 29.556 & 14.778 & 7.00 & 0.049 \\
\hline Feed & 2 & 160.222 & $80.83 \%$ & 160.222 & 80.111 & 37.95 & 0.003 \\
\hline Error & 4 & 8.444 & $4.26 \%$ & 8.444 & 2.111 & & \\
\hline Total & 8 & 198.222 & $100.00 \%$ & & & & \\
\hline \multicolumn{7}{|c|}{ Model Summary } \\
\cline { 2 - 5 } \\
\cline { 2 - 7 } & 1.45297 & R-sq R-sq(adj) R-sq(pred) & \\
\hline
\end{tabular}

conventional tools for $F_{x}, F_{y}$ and $F_{z}$. The force values along the $\mathrm{Z}$ axis are seen to deviate from the mean line conventional tools is clearly evident. the textured tools in comparison to the and distribution is not normal but the model could be said

as robust

from the results

obtained from the ANOVA test results. Through the Anderson Darling test, the values of forces along $\mathrm{x}, \quad \mathrm{y}, \quad \mathrm{z}$ directions are seen to be accurate and lying in between the upper and lower boundaries and also the highest value of $P$ could be noticed in case of

thrust force which is the force along Table 11. (a) Analysis of Variance Fx (Conventional)

\begin{tabular}{|c|c|c|c|c|c|c|c|}
\hline Source & DF & Seq SS & Contribution & Adj SS & Adj MS & F-Value & P-Value \\
\hline Cutting Speed & 2 & 14.00 & $0.63 \%$ & 14.00 & 7.00 & 1.08 & 0.422 \\
\hline Feed & 2 & 2198.00 & $98.21 \%$ & 2198.00 & 1099.00 & 169.08 & 0.000 \\
\hline Error & 4 & 26.00 & $1.16 \%$ & 26.00 & 6.50 & & \\
\hline Total & 8 & 2238.00 & $100.00 \%$ & & & & \\
\hline \multicolumn{7}{|c|}{ Model Summary } \\
\cline { 2 - 5 } \\
\cline { 2 - 5 } & 2.5 R-sq-sq(adj) R-sq(pred) & 98.84\% 97.68\% 94.12\% & \\
\hline
\end{tabular}

Table 11. (c) Analysis of Variance Fy (Conventional)

\begin{tabular}{|c|c|c|c|c|c|c|c|}
\hline Source & DF & Seq SS & Contribution & Adj SS & Adj MS & F-Value & P-Value \\
\hline Cutting speed & 2 & 29.556 & $14.91 \%$ & 29.556 & 14.778 & 7.00 & 0.049 \\
\hline Feed & 2 & 160.222 & $80.83 \%$ & 160.222 & 80.111 & 37.95 & 0.003 \\
\hline Error & 4 & 8.444 & $4.26 \%$ & 8.444 & 2.111 & & \\
\hline Total & 8 & 198.222 & $100.00 \%$ & & & & \\
\hline \multicolumn{7}{|c|}{ Model Summary } \\
\cline { 2 - 5 } \\
\cline { 2 - 6 } & R-sq-sq(adj) R-sq(pred) & R & \\
\hline
\end{tabular}

Table 11. (b) Analysis of Variance Fx (Textured)

$\mathrm{Y}$ axis. Moreover, the highest deviation of $\mathrm{P}$ values also could be noticed in case of the thrust force which proves that the effect of dimpling is significant in thrust forces. Similar behaviour is also noticed for the probability plots for surface roughness values for both textured as well as patterned tools as shown in Fig 7. The results clearly show better $\mathrm{P}$ values for roughness with dimpled tools and the values were seen fitting the model which was verified through Anderson Darling Test. Thus, the effectiveness of 
Table 11. (e) Analysis of Variance Fz (Conventional)

\begin{tabular}{|c|c|c|c|c|c|c|c|}
\hline Source & DF & Seq SS & Contribution & Adj SS & Adj MS & F-Value & P-Value \\
\hline Cutting Speed & 2 & 36.2 & $0.23 \%$ & 36.2 & 18.11 & 1.17 & 0.397 \\
\hline Feed & 2 & 15833.6 & $99.38 \%$ & 15833.6 & 7916.78 & 512.60 & 0.000 \\
\hline Error & 4 & 61.8 & $0.39 \%$ & 61.8 & 15.44 & & \\
\hline Total & 8 & 15931.6 & $100.00 \%$ & & & & \\
\hline \multicolumn{7}{|c|}{ Model Summary } \\
\cline { 2 - 5 } \\
\cline { 2 - 6 } & R 2.54951 & $98.84 \%$ R-sq(adj) R-sq(pred) & R7.68\% 94.12\% \\
\hline
\end{tabular}

Table 11. (f) Analysis of Variance Fz (Textured)

\begin{tabular}{|c|c|c|c|c|c|c|c|}
\hline Source & DF & Seq SS & Contribution & Adj SS & Adj MS & F-Value & P-Value \\
\hline Cutting Speed & 2 & 176.2 & $1.26 \%$ & 176.2 & 88.11 & 2.18 & 0.229 \\
\hline Feed & 2 & 13660.2 & $97.59 \%$ & 13660.2 & 6830.11 & 168.88 & 0.000 \\
\hline Error & 4 & 161.8 & $1.16 \%$ & 161.8 & 40.44 & & \\
\hline Total & 8 & 13998.2 & $100.00 \%$ & & & & \\
\hline \multicolumn{7}{|c|}{ Model Summary } \\
\cline { 2 - 5 } & \multicolumn{7}{|c|}{ R-sq R-sq(adj) R-sq(pred) } \\
\cline { 2 - 6 } & 6.35959 & $98.84 \% \quad 97.69 \%$ & $94.15 \%$ & \\
\hline
\end{tabular}

Table 12. (a) Analysis of Variance Ra (Conventional)

\begin{tabular}{|c|c|c|c|c|c|c|c|}
\hline Source & DF & Seq SS & Contribution & Adj SS & Adj MS & F-Value & P-Value \\
\hline Cutting Speed & 2 & 0.04805 & $21.16 \%$ & 0.04805 & 0.024026 & 8.18 & 0.039 \\
\hline Feed & 2 & 0.16730 & $73.67 \%$ & 0.16730 & 0.083649 & 28.48 & 0.004 \\
\hline Error & 4 & 0.01175 & $5.17 \%$ & 0.01175 & 0.002937 & & \\
\hline Total & 8 & 0.22710 & $100.00 \%$ & & & & \\
\cline { 2 - 5 } & \multicolumn{7}{|c|}{ Model Summary } \\
\cline { 2 - 7 } & 0.0541926 & R-sq R-sq(adj) R-sq(pred) & & \\
\hline
\end{tabular}

Table 12. (b) Analysis of Variance Ra (Textured)

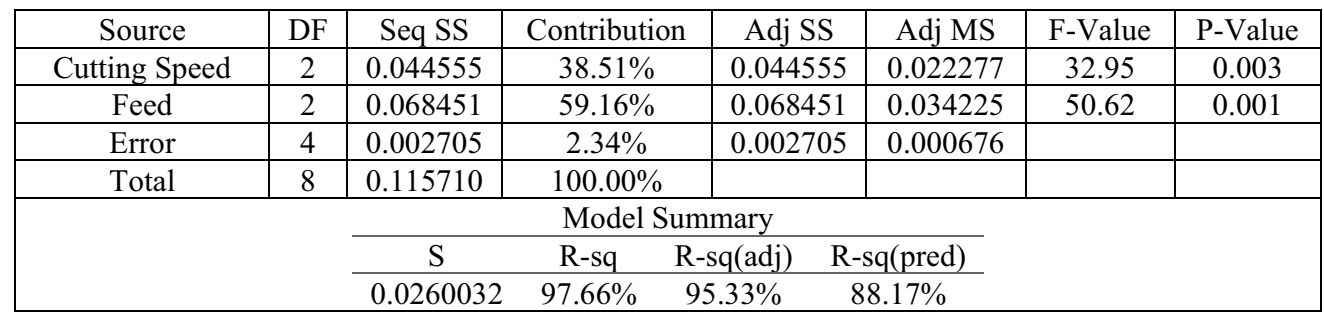

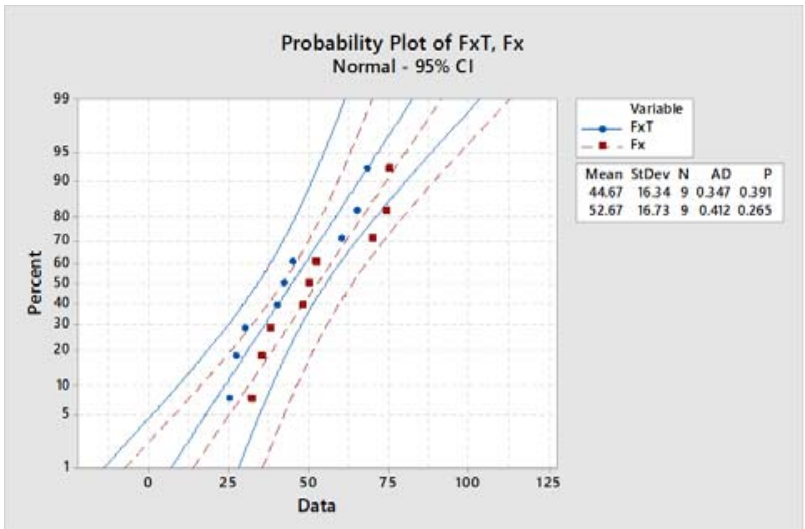

Fig. 6. (a) Probability plots for $\mathrm{Fx}$ (Textured) Vs. Fx (Conventional) 


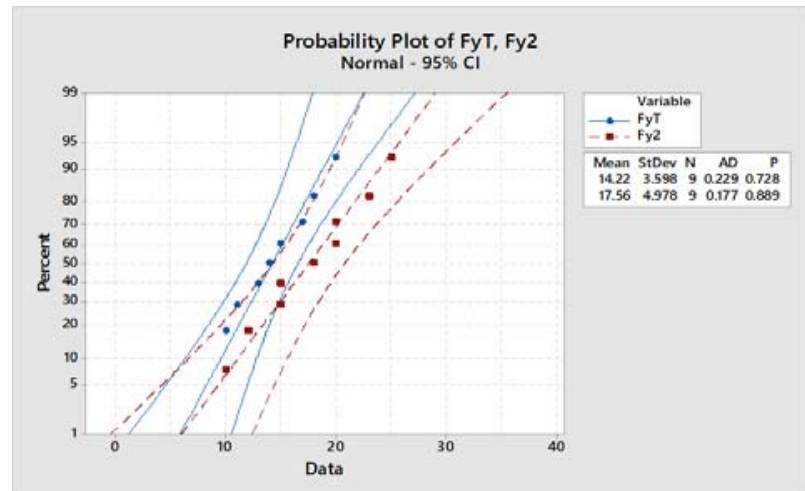

Fig. 6. (b) Probability plots for Fy (Textured) Vs. Fy (Conventional)

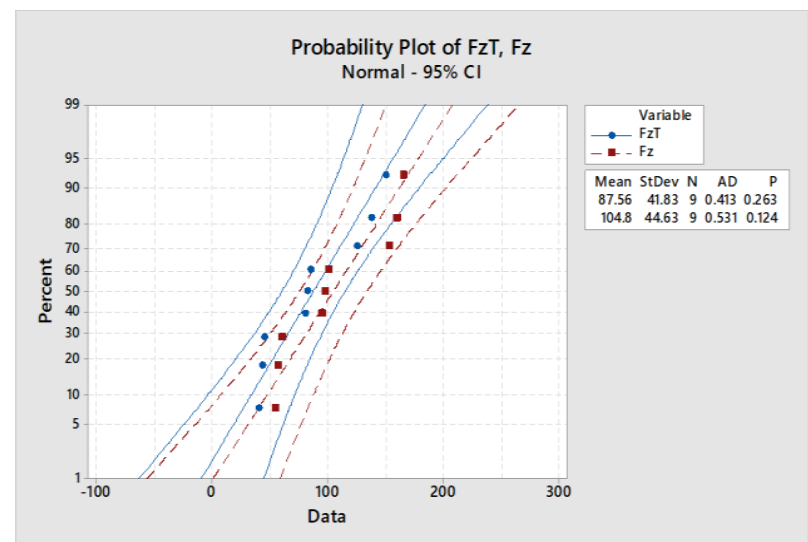

Fig. 6. (c) Probability plots for Fz (Textured) Vs. Fz (Conventional)

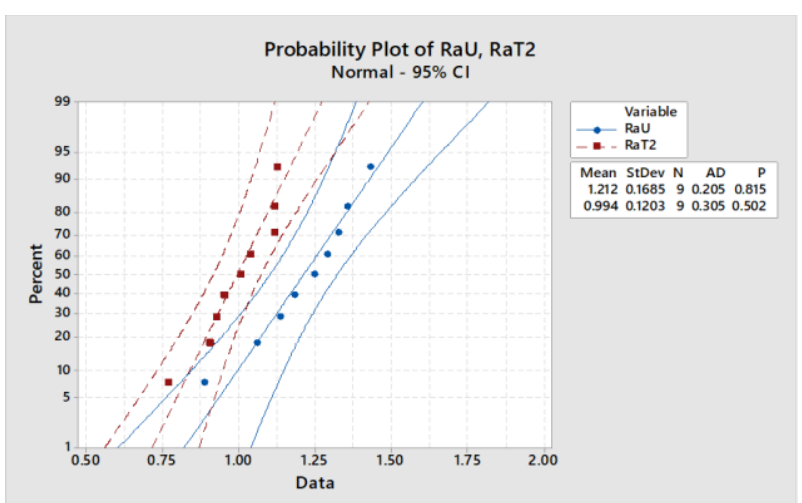

Fig. 7. Probability plots for $\mathrm{Ra}$ (Textured) Vs. Ra (Conventional)

\subsection{Optimal Parametric Levels}

The predicted optimum value for cutting forces using both textured as well as non-textured tools is at cutting speed of $150 \mathrm{~m} / \mathrm{min}$ and feed of $0.045 \mathrm{~mm} / \mathrm{rev}$. Similarly, the predicted optimum value for surface roughness using both textured as well as non-textured tools is at cutting speed of $100 \mathrm{~m} / \mathrm{min}$ and feed of $0.045 \mathrm{~mm} / \mathrm{rev}$. The predicted values of forces along $\mathrm{x}, \mathrm{y}, \mathrm{z}$ axis for both conventional as well as patterned tools and the predicted surface roughness values for both conventional as well as patterned tools are mentioned in Table 13 and Table 14, respectively.

Table 13. (a) Predicted Cutting Forces (Conventional)

\begin{tabular}{|c|c|c|c|c|}
\hline Response & Fit & $\begin{array}{c}\text { SE } \\
\text { Fit }\end{array}$ & $95 \%$ CI & $95 \%$ PI \\
\hline Fx & 33.67 & 1.90 & $28.39,38.94$ & $\begin{array}{c}24.84, \\
42.50\end{array}$ \\
\hline Fy & 10.44 & 1.08 & $7.44,13.45$ & $\begin{array}{c}5.41, \\
15.48\end{array}$ \\
\hline Fz & 54.56 & 2.93 & $46.42,62.69$ & $\begin{array}{c}40.95, \\
68.16\end{array}$ \\
\hline
\end{tabular}

Table 13. (b) Predicted Cutting Forces (Textured)

\begin{tabular}{|c|c|c|c|c|}
\hline Response & Fit & $\begin{array}{c}\text { SE } \\
\text { Fit }\end{array}$ & $95 \%$ CI & $95 \%$ PI \\
\hline Fx & 26.00 & 2.62 & $18.73,33.27$ & $\begin{array}{c}13.84, \\
38.16\end{array}$ \\
\hline Fy & 10.11 & 0.994 & $7.352,12.870$ & $\begin{array}{c}5.494, \\
14.728\end{array}$ \\
\hline Fz & 36.78 & 4.74 & $23.62,49.94$ & $\begin{array}{c}14.76, \\
58.80\end{array}$ \\
\hline
\end{tabular}

Table 14. (a) Predicted results for Ra (Conventional)

\begin{tabular}{|c|c|c|c|c|}
\hline Response & Fit & SE Fit & $95 \%$ CI & $95 \%$ PI \\
\hline $\mathrm{Ra}$ & 0.944 & 0.0404 & 0.8319, & 0.7563, \\
& & & 1.0561 & 1.1317 \\
\hline
\end{tabular}

Table 14. (b) Predicted results for Ra (Textured)

\begin{tabular}{|c|c|c|c|c|}
\hline Response & Fit & SE Fit & $95 \%$ CI & $95 \%$ PI \\
\hline $\mathrm{Ra}$ & 0.778 & 0.0194 & $0.7242,0.8318$ & 0.688, \\
& & & & 0.868 \\
\hline
\end{tabular}

The corresponding Cutting Forces Optimization Plots and the Surface Roughness Optimization Plots are also shown 
in Fig 8 (a)-(b) and Fig 9 (a)-(b), respectively for conventional as well as patterned tools.

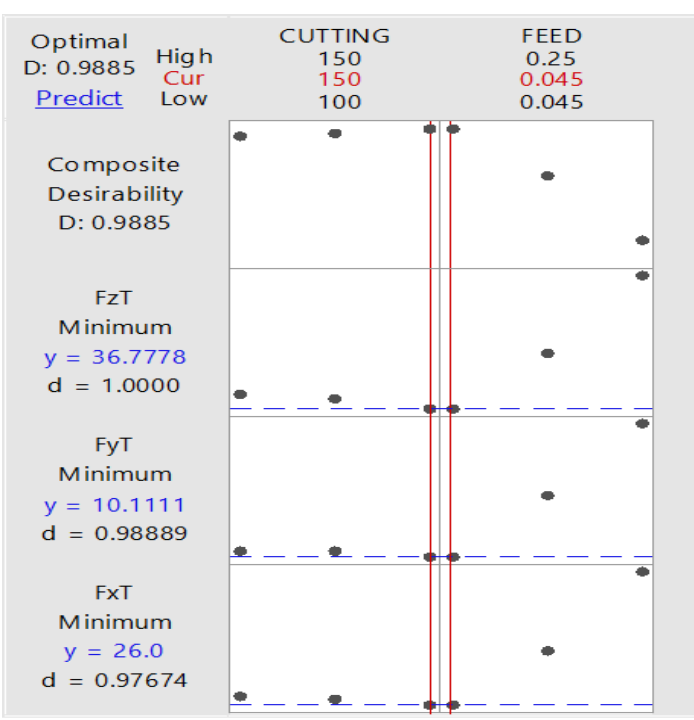

(a)

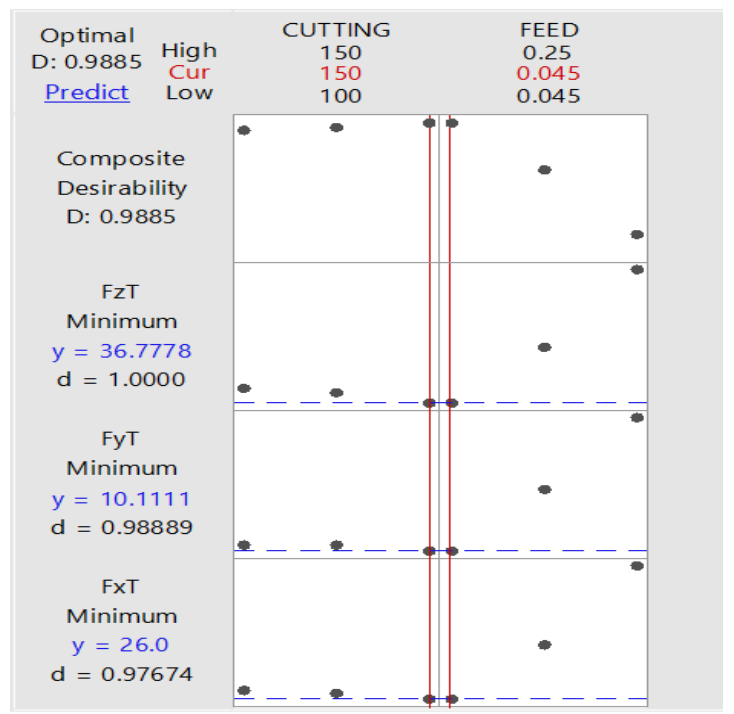

(b)

Fig. 8. Cutting Forces Optimization Plots (a) Conventional (b) Patterned

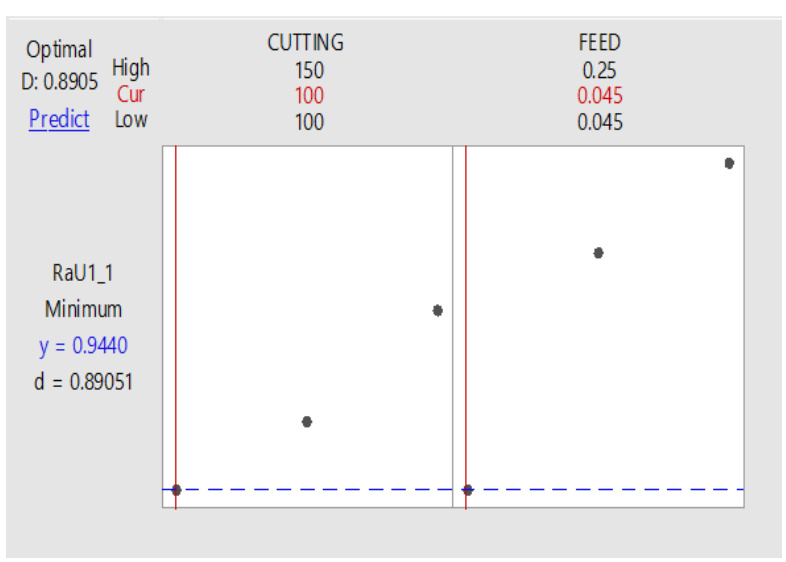

(a)

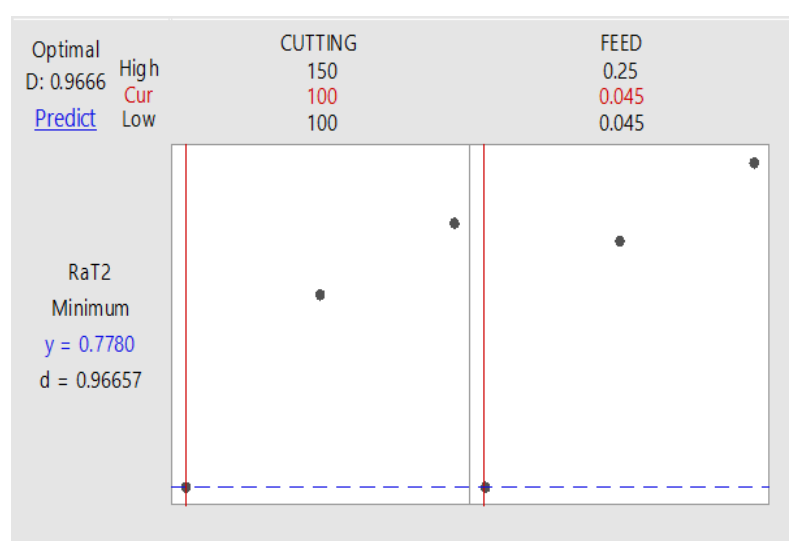

(b)

Fig. 9. Surface Roughness Optimization Plots (a) Conventional (b) Patterned

\section{Conclusion}

The effect of dimple type surface texturing on the on the rake surface of HSS T42 S400 tool during the dry turning operation of pure aluminium have been investigated. The desired dimples are perforated via micromachining with the aid of the pulsed Nd: YAG laser. The cutting forces and surface roughness are investigated by performing dry turning operation using the present textured as well as untextured tools based on Taguchi methodology. The useful observations made during the analysis are as follows:

1. Shallow and deep dimples with higher amount of metal deposition on the edges can be produced on the rake surface of the HSS tool by using pulsed Nd: YAG laser.

2. The feed has been proved to be more effective factor in comparison to the cutting speed, so far as the influence on the cutting forces and the surface roughness during dry turning operation is concerned.

3. The predicted optimized values for cutting speed and feed are found to be $(150 \mathrm{~mm} / \mathrm{min}, 0.045 \mathrm{~mm} / \mathrm{rev})$ and $(100 \mathrm{~mm} / \mathrm{min}, 0.045 \mathrm{~mm} / \mathrm{rev})$ for the cutting force and surface roughness analysis, respectively.

4. F-value and P-value in ANOVA showed that cutting speed is of less importance than feed for all forces along $\mathrm{x}, \mathrm{y}$ and $\mathrm{z}$ directions for both textured and conventional tools.

5. For surface roughness analysis in ANOVA, it is observed that the values of $\mathrm{F}$ are more than 4 for both the cutting speed and feed, hence both the parameters could be said to be significant but the value of $F$ is more in feed showing feed as more significant in comparison to cutting speed. The same can also be observed for the $\mathrm{P}$ values showing feed to be more significant for both the conventional as well as the dimpled tools.

6. From the probability plots, it is observed that the dimpled tools are providing better values than conventional tools for both cutting forces and surface roughness. 


\section{References}

1. M. S. Carrilero, R. Bienvenido, J. M. Sánchez, M. Álvarez, A. González, and M. Marcos, Int. J. Mach. Tools Manuf., 42, 215 (2002).

2. M. Nouari, G. List, F. Girot, and D. Coupard, Wear, 255, 1359 (2003)

3. W. Grzesik and T. Wanat, Int. J. Mach. Tools Manuf., 46,1988 (2006)

4. M. Asad, H. Ijaz, M. A. Khan, T. Mabrouki, and W. Saleem, Proc. Inst. Mech. Eng. Part B J. Eng. Manuf. 228, 367 (2014)

5. O. Lee, H. B. Choi, and H.-M. Kim, Journal of Mechanical Science and Technology, 25, 143 (2011)

6. A. Narasimhulu, V. R. Paruchuri, and S. Ghosh, "Dry Machining of Ti-6Al-4V using PVD coated TiAlN Tools," Proceedings of the World Congress on Engineering, London, U.K, 2012

7. A. Gómez-Parra, M. Álvarez-Alcón, J. Salguero, M. Batista, and M. Marcos, Wear, 302, 1209 (2013)

8. C. Kalyan and G. L. Samuel, J. Mater. Process. Technol. 216, 146 (2015)

9. A. Torres, I. Puertas, and C. J. Luis, Procedia Eng., 132, 537 (2015).

10. J. Eapen, S. Murugappan, and A. Sanjivi, Mater. Today Proc., 4, 7686 (2017)

11. S. K. Pattnaik, N. K. Bhoi, S. Padhi, and S. K. Sarangi, Int. J. Adv. Manuf. Technol., 98, 55 (2018).

12. R. Teimouri, S. Amini, and N. Mohagheghian, J. Manuf. Process., 26, 1 (2017).

13. Shi C, Yu A, Wu J, Niu W, He Y, Hong X, Shang Q. Int. J. Mach. Tools Manuf., 122, 132 (2007).

14. K. Surya Sundara Rao and K. Viswanath Allamraju, Mater. Today Proc., 4, 975 (2017).

15. Y. Chen, Y. Yang, Z. Feng, B. Huang, and X. Luo, J. Alloys Compd., 726, (2017).

16. S. K. I. and A. Ghosh, J. Mater. Process. Technol., 252, 280 (2018)

17. T. Sugihara and T. Enomoto, Precis. Eng., 33, 425 (2009).

18. T. Enomoto and T. Sugihara, CIRP Ann., 59, 597 (2010).

19. T. Obikawa, A. Kamio, H. Takaoka, and A. Osada, Int. J. Mach. Tools Manuf., 51,966 (2011)

20. W. Ze, D. Jianxin, C. Yang, X. Youqiang, and Z. Jun, Int. J. Adv. Manuf. Technol. 62, 943 (2012).

21. T. Sugihara and T. Enomoto, Precis. Eng., 37, 888 (2013).

22. Johannes Kümme, Daniel Brauna, Jens Gibmeier, Johannes Schneider, Christian Greiner, Volker Schulzea, Alexander Wanner, J. Mater. Process. Technol., 215, 62 (2015)

23. R. Kurniawan, G. Kiswanto, and T. J. Ko, Int. J. Mach. Tools Manuf., 106, 127 (2016).

24. D. Arulkirubakaran and V. Senthilkumar, Int. J. Refract. Met. Hard Mater., 62, 47 (2017).
25. R. Sasi, S. Subbu, and P. Anand iyamperumal, Surf. Coat. Technol., 313, (2017).

26. C. Zhang, G. Shi, and K. F. Ehmann, Int. J. Mach. Tools Manuf.,120, 72 (2017)

27. S. Dhage, A. D. Jayal, and P. Sarkar, Procedia Manuf., 33,794(2019).

28. M. Law, R. Karthik, S. Sharma, and J. Ramkumar, J. Manuf. Process., 60,144 (2020).

29. Q. Li, C. Pan, Y. Jiao, and K. Hu, Micromachines, 10, 352 (2019).

30. S. K. Rajbongshi and D. K. Sarma, Int. J. Refract. Met. Hard Mater., 83, 1049709 (2019). 